\title{
Co-expressed differentially expressed genes and long non-coding RNAs involved in the celecoxib treatment of gastric cancer: An RNA sequencing analysis
}

\author{
BIN SONG $^{1}$, JUAN DU ${ }^{2}$, YE FENG $^{1}$, YONG-JIAN GAO ${ }^{1}$ and JI-SHENG ZHAO ${ }^{1}$ \\ ${ }^{1}$ Department of Gastrointestinal Surgery, China-Japan Union Hospital, Jilin University; \\ ${ }^{2}$ Department of Medical Oncology, The Tumor Hospital of Jilin, Changchun, Jilin 130033, P.R. China
}

Received February 26, 2015; Accepted May 26, 2016

DOI: $10.3892 /$ etm.2016.3648

\begin{abstract}
The aim of the present study was to investigate the mechanisms of long non-coding RNAs (lncRNAs) in a gastric cancer cell line treated with celecoxib. The human gastric carcinoma cell line NCI-N87 was treated with $15 \mu \mathrm{M}$ celecoxib for $72 \mathrm{~h}$ (celecoxib group) and an equal volume of dimethylsulfoxide (control group), respectively. Libraries were constructed by NEBNext Ultra RNA Library Prep kit for Illumina. Paired-end RNA sequencing reads were aligned to a human hg19 reference genome using TopHat2. Differentially expressed genes (DEGs) and lncRNAs were identified using Cuffdiff. Enrichment analysis was performed using $\mathrm{GO}$-function package and KEGG profile in Bioconductor. A protein-protein interaction network was constructed using STRING database and module analysis was performed using ClusterONE plugin of Cytoscape. ATP5G1, ATP5G3, COX8A, CYC1, NDUFS3, UQCRC1, UQCRC2 and UQCRFS1 were enriched in the oxidative phosphorylation pathway. $C X C L 1$, $C X C L 3, C X C L 5$ and $C X C L 8$ were enriched in the chemokine signaling and cytokine-cytokine receptor interaction pathways. ITGA3, ITGA6, ITGB4, ITGB5, ITGB6 and ITGB8 were enriched in the integrin-mediated signaling pathway. DEGs co-expressed with lnc-SCD-1:13, lnc-LRR1-1:2, lnc-PTMS-1:3, lnc-S100P-3:1, lnc-AP000974.1-1:1 and
\end{abstract}

Correspondence to: Dr Ji-Sheng Zhao, Department of Gastrointestinal Surgery, China-Japan Union Hospital, Jilin University, 126 Xiantai Road, Changchun, Jilin 130033, P.R. China E-mail: jizsheng@163.com

Abbreviations: lncRNAs, long non-coding RNAs; DEGs, differentially expressed genes; PPI, protein-protein interaction; ncRNAs, non-coding RNAs; miRNAs, microRNAs; DMSO, dimethylsulfoxide; QC, quality control; NGS, next generation sequencing; GO, gene ontology; $\mathrm{BP}$, biological process; $\mathrm{CC}$, cellular component; $\mathrm{MF}$, molecular function; mPTP, mitochondrial permeability transition pore

Key words: celecoxib, gastric cancer, differentially expressed genes, enrichment analysis
lnc-RAB3IL1-2:1 were enriched in the pathways associated with cancer, such as the basal cell carcinoma pathway in cancer. In conclusion, these DEGs and differentially expressed lncRNAs may be important in the celecoxib treatment of gastric cancer.

\section{Introduction}

Despite the mortality rate for gastric carcinoma reducing $3.1 \%$ annually and the overall 5-year relative survival rate increasing to $28 \%$ over the past 10 years, the mortality rate for gastric carcinoma remains $>50 \%$ worldwide (1). The most effective treatment for resectable gastric cancer is surgery, which presents good survival rates. The majority of cases of gastric cancer are diagnosed at an advanced stage or as a relapse after surgery (2). Therefore, a further understanding of the molecular mechanisms of gastric cancer is of clinical importance and it is required in order to improve the early diagnosis and therapeutic strategies of gastric cancer.

Over the last decade, the majority of the potential therapeutic targets reported and the diagnostic markers for gastric cancer are protein-coding genes identified from large-scale DNA microarray analysis, including the novel genes $K L F 5$, FAT4, KMT2C, GATA4, MLL and GATA6 (3-6). The majority of studies on non-coding RNAs (ncRNAs) are focused on short ncRNAs called microRNAs, while alterations in the structure, expression levels and cognate RNA-binding proteins of long ncRNAs (lncRNAs) with a length of >200 nucleotides (nt) have been associated with cancer, and appear to be gaining prominence as further studies are conducted (7). In addition, growing evidence has confirmed that lncRNAs that are capable of regulating tumor suppression or that exhibit oncogenic effects may be considered as novel biomarkers and therapeutic targets for cancer $(8,9)$. Furthermore, it has been demonstrated that differentially expressed long non-coding RNAs (DE-lncRNAs), including H19 and uc001lsz, may present potential roles in the development and occurrence of gastric cancer (10). In a study by Hu et al (11), a novel lncRNA GAPLINC (924 bp) was highly expressed in gastric cancer specimens and it was capable of controlling the expression levels of CD44 to regulate cell invasion by competing for miR211-3p. 
Table I. Differentially expressed lncRNAs in the celecoxib and the control groups.

\begin{tabular}{|c|c|c|c|c|}
\hline lncRNAs ID & Celecoxib & Control & Fold change & q value \\
\hline \multicolumn{5}{|l|}{ Upregulated } \\
\hline lnc-IGFL3-2:1 & 18.43 & 44.60 & 1.27 & $1.07 \times 10^{-7}$ \\
\hline lnc-PTMS-1:3 & 427.83 & 613.56 & 0.52 & $1.71 \times 10^{-6}$ \\
\hline lnc-SCD-1:13 & 105.06 & 152.80 & 0.54 & $1.71 \times 10^{-6}$ \\
\hline lnc-TNS4-2:1 & 6.28 & 15.94 & 1.34 & $1.71 \times 10^{-6}$ \\
\hline lnc-TTLL10-3:1 & 7.71 & 11.67 & 0.60 & $2.91 \times 10^{-5}$ \\
\hline lnc-CKMT1A-1:1 & 50.37 & 97.92 & 0.96 & $5.80 \times 10^{-5}$ \\
\hline lnc-LRR1-1:2 & 4422.95 & 5914.51 & 0.42 & $6.36 \times 10^{-5}$ \\
\hline lnc-RAB3IL1-2:1 & 2279.25 & 3231.60 & 0.50 & $7.18 \times 10^{-4}$ \\
\hline lnc-JUNB-1:1 & 372.34 & 562.08 & 0.59 & $2.00 \times 10^{-3}$ \\
\hline lnc-RP11-259P6.1.1-2:1 & 29.78 & 39.57 & 0.41 & $3.20 \times 10^{-3}$ \\
\hline lnc-IGFL2-2:1 & 105.84 & 167.35 & 0.66 & $5.76 \times 10^{-3}$ \\
\hline lnc-S100P-3:1 & 142.85 & 240.91 & 0.75 & $6.65 \times 10^{-3}$ \\
\hline lnc-SRGAP3-1:29 & 0 & 1.73 & $1.80 \mathrm{e}+308$ & $1.19 \times 10^{-2}$ \\
\hline lnc-RAB44-3:1 & 8.43 & 14.88 & 0.82 & $1.25 \times 10^{-2}$ \\
\hline lnc-GLTSCR2-2:7 & 18.58 & 26.75 & 0.53 & $1.26 \times 10^{-2}$ \\
\hline lnc-PDZD7-3:2 & 0 & 3.41 & $1.80 \mathrm{e}+308$ & $2.41 \times 10^{-2}$ \\
\hline lnc-CEACAM6-1:1 & 33.20 & 57.59 & 0.79 & $2.51 \times 10^{-2}$ \\
\hline lnc-SPNS3-1:3 & 18.58 & 27.11 & 0.54 & $4.89 \times 10^{-2}$ \\
\hline lnc-UNC5B-1:1 & 12.62 & 18.20 & 0.53 & $4.89 \times 10^{-2}$ \\
\hline \multicolumn{5}{|l|}{ Downregulated } \\
\hline lnc-C9orf16-2:1 & 875.46 & 425.36 & -1.04 & 0 \\
\hline lnc-C9orf16-3:1 & 352.54 & 156.14 & -1.17 & 0 \\
\hline lnc-TRIM31-1:2 & 47.17 & 21.45 & -1.14 & $4.10 \times 10^{-8}$ \\
\hline lnc-DDX47-3:1 & 211.38 & 145.19 & -0.54 & $1.46 \times 10^{-7}$ \\
\hline lnc-PCK1-3:1 & 13.92 & 5.48 & -1.35 & $8.52 \times 10^{-7}$ \\
\hline lnc-MYO16-7:1 & 349.12 & 200.98 & -0.80 & $1.71 \times 10^{-6}$ \\
\hline lnc-YPEL5-5:1 & 71.82 & 44.54 & -0.69 & $1.71 \times 10^{-6}$ \\
\hline lnc-TNK2-8:1 & 16.60 & 2.33 & -2.83 & $4.54 \times 10^{-6}$ \\
\hline lnc-AC069257.9.1-4:73 & 124.40 & 66.92 & -0.90 & $6.69 \times 10^{-5}$ \\
\hline lnc-CCDC80-1:4 & 18.79 & 3.17 & -2.57 & $1.74 \times 10^{-3}$ \\
\hline lnc-AC069257.9.1-4:72 & 151.58 & 81.26 & -0.90 & $5.89 \times 10^{-3}$ \\
\hline lnc-KRT36-1:1 & 45.00 & 18.61 & -1.27 & $6.65 \times 10^{-3}$ \\
\hline lnc-CCDC33-1:1 & 32.45 & 19.88 & -0.71 & $8.64 \times 10^{-3}$ \\
\hline lnc-CXCL3-1:1 & 5.06 & 1.51 & -1.74 & $2.51 \times 10^{-2}$ \\
\hline lnc-PDZK1IP1-3:1 & 25.26 & 11.57 & -1.13 & $3.28 \times 10^{-2}$ \\
\hline lnc-SUSD3-4:2 & 19.48 & 9.17 & -1.09 & $3.37 \times 10^{-2}$ \\
\hline lnc-AC069257.9.1-4:53 & 99.18 & 57.43 & -0.79 & $3.59 \times 10^{-2}$ \\
\hline lnc-AP000974.1-1:1 & 36.09 & 16.13 & -1.16 & $4.79 \times 10^{-2}$ \\
\hline
\end{tabular}

Celecoxib and control columns indicate the average expression values of the lncRNAs in the celecoxib and the control group, respectively. lncRNA, long non-coding ribonucleic acids.

A previous study demonstrated that celecoxib induced apoptosis and autophagy of gastric cancer SGC-7901 cells via the PI3K/Akt signaling pathway (12). According to a study by Lan et al (13), celecoxib inhibited Helicobacter pylori-induced invasion in gastric cancer via the adenine nucleotide translocator-dependent pathways. Furthermore, the activated Notch1 signaling pathway may contribute to the pathogenesis of gastric cancer, at least partly through $C O X-2$ (14). Treatment with celecoxib, a $C O X-2$ inhibitor, can significantly reduce the incidence of gastric cancer in rats (15). In addition, an elevated $C O X-2$ expression level is an independent prognostic factor indicative of poor prognosis and it is associated with reduced survival in patients with gastric cancer (16). Pang et al (17) reported that the Akt/GSK3ß/NAG-1 signaling pathway may be considered as the major mechanism of the $C O X$-2-independent 
Table II. Top five enriched gene ontology terms in biological process, cellular component and molecular function categories for upregulated DEGs.

\begin{tabular}{|c|c|c|c|c|}
\hline GO_ID & Term & Count & P-value & DEGs \\
\hline GO:0044281 & $\begin{array}{l}\text { Small molecule } \\
\text { metabolic process }\end{array}$ & 99 & $1.87 \times 10^{-9}$ & $\begin{array}{l}A B C C 3, A C A A 1, B 3 G N T 3, C D 320, D D X 11, \\
E C H S 1, F A 2 H, G A P D H, U Q C R F S 1, W N T 11^{a}\end{array}$ \\
\hline GO:0055114 & $\begin{array}{l}\text { Oxidation-reduction } \\
\text { process }\end{array}$ & 44 & $9.79 \times 10^{-9}$ & $\begin{array}{l}A C A A 1, A C S S 2, C O X 8 A, E C H S 1, F A 2 H, H M O X 1, \\
U Q C R C 1, U Q C R C 2, U Q C R F S 1, V A T 1^{a}\end{array}$ \\
\hline GO:0044710 & $\begin{array}{l}\text { Single-organism } \\
\text { metabolic process }\end{array}$ & 137 & $3.01 \times 10^{-8}$ & $\begin{array}{l}A B C C 3, A C A A 1, B 3 G N T 3, B M P 4, P C B D 1, \\
P S M D 8, R H O B, V A T 1, W N T 11, X R C C 6^{a}\end{array}$ \\
\hline GO:0043436 & $\begin{array}{l}\text { Oxoacid } \\
\text { metabolic process }\end{array}$ & 44 & $6.07 \times 10^{-8}$ & $\begin{array}{l}A B C C 3, A C A A 1, B 3 G N T 3, C K M T 1 A, E C H S 1, \\
S O D 1, S U L T 2 B 1, T P I 1, T S T, U G T 1 A 6^{a}\end{array}$ \\
\hline GO:0006082 & $\begin{array}{l}\text { Organic acid } \\
\text { metabolic process }\end{array}$ & 44 & $9.50 \times 10^{-8}$ & $\begin{array}{l}A B C C 3, A C A A 1, B 3 G N T 3, C K M T 1 A, G O T 1, \\
\text { SERINC2, SLC2A1, TPI1, TST, UGT1A6 } 6^{a}\end{array}$ \\
\hline
\end{tabular}

B, Cellular component

\begin{tabular}{|c|c|c|c|c|}
\hline GO_ID & Term & Count & P-value & DEGs \\
\hline GO:0005576 & Extracellular region & 138 & $3.64 \times 10^{-23}$ & $\begin{array}{l}\text { ADIRF, BMP4, CAPG, ILIRN, ITGA3, ITGA6, } \\
\text { ITGB4, ITGB5, VAT1,VDAC1 }\end{array}$ \\
\hline GO:0031982 & Vesicle & 129 & $5.68 \times 10^{-20}$ & $\begin{array}{l}\text { ADIRF, AHNAK2, ENO1, ITGA3, ITGB4, ITGB5, } \\
\text { SFN, UQCRC2, VASP, VAT1 }{ }^{a}\end{array}$ \\
\hline GO:0031988 & Membrane-bounded vesicle & 126 & $4.25 \times 10^{-18}$ & $\begin{array}{l}\text { ADIRF, ATP6AP1, BAIAP2L2, CAPG, EPS8L1, } \\
\text { FTH1, FURIN, GAPDH, UQCRC2, VASP }\end{array}$ \\
\hline GO:0043230 & Extracellular organelle & 118 & $2.21 \times 10^{-18}$ & $\begin{array}{l}\text { ADIRF, GOT1, ITGA3, ITGB4, ITGB5, KLK14, } \\
\text { UGT1A6, UPK3B, UQCRC2, VASP }\end{array}$ \\
\hline GO:0044421 & Extracellular region & 131 & $8.27 \times 10^{-13}$ & $\begin{array}{l}\text { ADIRF, HMOX1, ILIRN, ITGA3, ITGA6, ITGB4, } \\
\text { ITGB5, KLK14,TXN,WNT11 }{ }^{a}\end{array}$ \\
\hline
\end{tabular}

C, Molecular function

\begin{tabular}{|c|c|c|c|c|}
\hline GO_ID & Term & Count & P-value & DEGs \\
\hline GO:0005515 & Protein binding & 182 & $7.34 \times 10^{-7}$ & $\begin{array}{l}\text { AATK, HSP90AA1, IRF } 2 B P 1, I T G A 3, I T G A 6, \\
I T G B 4, I T G B 5, \text { UQCRFS1, VASP, VDAC1 }{ }^{a}\end{array}$ \\
\hline GO:0016491 & Oxidoreductase activity & 31 & $9.29 \times 10^{-7}$ & $\begin{array}{l}\text { ACAA1, GAPDH, HMOX1, HPDL, HR, LDHA, } \\
M A O B, N D U F S 3, P C B D 1, P^{a}\end{array}$ \\
\hline GO:0043236 & Laminin binding & 6 & $7.96 \times 10^{-6}$ & ECM1, GPC1, ITGA3, ITGA6, LGALS1, LYPD3 \\
\hline GO:0050840 & $\begin{array}{l}\text { Extracellular matrix } \\
\text { binding }\end{array}$ & 7 & $2.07 \times 10^{-5}$ & $\begin{array}{l}\text { ECM1, GPC1, GPR56, ITGA3, ITGA6, } \\
L G A L S 1, L Y P D 3\end{array}$ \\
\hline GO:0008106 & $\begin{array}{l}\text { Alcohol dehydrogenase } \\
\left(\mathrm{NADP}^{+}\right) \text {activity }\end{array}$ & 4 & $3.68 \times 10^{-5}$ & $A K R 1 B 1, A K R 1 C 2, A K R 1 C 3, A L D H 3 A 1$ \\
\hline
\end{tabular}

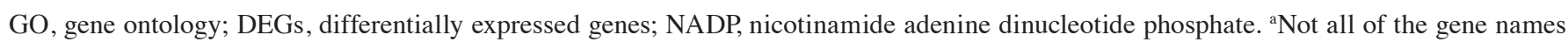
were included in the table.

effects of celecoxib on gastric cancer cells. $C O X-2$ has been indicated to regulate E-cadherin expression via the $\mathrm{NF}-\kappa \mathrm{B}$ and Snail signaling pathway in gastric cancer (18). It has also been reported that celecoxib has the potential for clinical use in gastric cancer treatment by the mechanism of activating miR-29c (19). Although various advances have been made in the study of mechanisms of lncRNAs in gastric cancer, the understanding of the expression patterns and functional roles of lncRNAs in gastric cancer treated with celecoxib requires further investigation.

In the present study, the RNA sequencing data of NCI-N87 human gastric carcinoma cells treated with or 
Table III. Top five enriched gene ontology terms in the biological process, cellular component and molecular function categories for downregulated DEGs.

A, Biological process

\begin{tabular}{|c|c|c|c|c|}
\hline GO_ID & Term & Count & $\mathrm{P}$-value & DEGs \\
\hline GO:0009888 & Tissue development & 42 & $4.66 \times 10^{-8}$ & $\begin{array}{l}\text { ADAM9, ALDH1A3, FNDC } 3 B, \text { NTN4, PKP2, } \\
\text { RIPK4, TNFRSF19, TRIM16, TSC22D3, WNT7B }\end{array}$ \\
\hline GO:0048513 & Organ development & 58 & $1.90 \times 10^{-7}$ & $\begin{array}{l}\text { ADAM9, EGLN1, LTBP3, MAP } 3 K 1, M D K, N R I P 1, \\
\text { TNFRSF19, TNS3, TRIM16, TSC22D } 3^{a}\end{array}$ \\
\hline GO:0048731 & System development & 70 & $6.10 \times 10^{-7}$ & $\begin{array}{l}\text { ADAM9, SGPL1, TNFAIP2, TNFRSF19, TNS3, } \\
\text { TRIM16, TRIO, TSC22D3, WNT7B, ZSWIM6 }\end{array}$ \\
\hline GO:0048518 & $\begin{array}{l}\text { Positive regulation of } \\
\text { biological process }\end{array}$ & 74 & $6.85 \times 10^{-7}$ & $\begin{array}{l}\text { ADAM9, GLIS3, HSPB 1, IGFBP3, IRF1, } \\
\text { ITGB8, KLK6, TRIM16, TRIO,WNT7B }\end{array}$ \\
\hline GO:0009653 & $\begin{array}{l}\text { Anatomical structure } \\
\text { morphogenesis }\end{array}$ & 49 & $7.77 \times 10^{-7}$ & $\begin{array}{l}\text { ADAM9, MAP1B, MAP2, NTN4, PKP2, } \\
P T P R J, R I P K 4, S A T 1, S E M A 7 A, S G P L 1^{a}\end{array}$ \\
\hline
\end{tabular}

B, Cellular component

\begin{tabular}{|c|c|c|c|c|}
\hline GO_ID & Term & Count & P-value & DEGs \\
\hline GO:0044421 & Extracellular region & 73 & $1.02 \times 10^{-10}$ & $\begin{array}{l}\text { ADAM9, CCDC80, CLIC5, FRAS1, SNX18, } \\
\text { SOSTDC1, ST6GAL1, SULF2, TNFAIP2,VWA2 }{ }^{a}\end{array}$ \\
\hline GO:0005615 & Extracellular space & 35 & $1.02 \times 10^{-8}$ & $\begin{array}{l}\text { ADAM9, HSPG2, IGFBP3, MUC4, PLAT, POTEF, } \\
\text { SERPINA3, TNFAIP2, VWA2, WNT7B }{ }^{a}\end{array}$ \\
\hline GO:0005576 & Extracellular region & 77 & $1.78 \times 10^{-8}$ & $\begin{array}{l}\text { ADAM9, KRT15, LCN2, SLC7A5, SNX18, SOSTDC1, } \\
\text { ST6GAL1, SULF2, TACSTD2, TGM2 }\end{array}$ \\
\hline GO:0043230 & Extracellular organelle & 56 & $1.92 \times 10^{-8}$ & $\begin{array}{l}\text { ADAM9, IVL, KRT13, MYOF, PLAT, POTEF, } \\
\text { SLC7A5, SNX18, ST6GAL1, TACSTD2 }{ }^{a}\end{array}$ \\
\hline GO:0065010 & $\begin{array}{l}\text { Extracellular organelle, } \\
\text { membrane-bound }\end{array}$ & 56 & $1.92 \times 10^{-8}$ & $\begin{array}{l}\text { ADAM9, IGFBP3, LTBP3, MARCKS, SELENBP1, } \\
\text { SNX18, ST6GAL1, TGM2, THSD4, VWA2 }{ }^{a}\end{array}$ \\
\hline
\end{tabular}

C, Molecular function

\begin{tabular}{lllll}
\hline GO_ID & \multicolumn{1}{c}{ Term } & Count & P-value & \\
\hline GO:0005080 & Protein kinase C binding & 4 & $1.31 \times 10^{-3}$ & ADAM9, HSPB1, MARCKS, PKP2 \\
GO:0008009 & Chemokine activity & 4 & $1.42 \times 10^{-3}$ & CXCL1, CXCL3, CXCL5, CXCL8 \\
GO:0019838 & Growth factor binding & 6 & $1.43 \times 10^{-3}$ & BMPR2, CTGF, IGFBP3, IGFBP6, LTBP3, TRIM16 \\
GO:0031994 & $\begin{array}{l}\text { Insulin-like growth } \\
\text { factor I binding }\end{array}$ & 2 & $2.28 \times 10^{-3}$ & IGFBP3, IGFBP6 \\
GO:0055106 & Ubiquitin-protein & 2 & $2.28 \times 10^{-3}$ & CDKN2A, TRIB1 \\
& transferase regulator activity & & & \\
\hline
\end{tabular}

GO, gene ontology; DEGs, differentially expressed genes. ${ }^{a}$ Not all of the gene names were included in the table.

without celecoxib were prepared and analyzed using bioinformatics methods. Briefly, differentially expressed genes (DEGs) and lncRNAs were identified for pathway enrichment analysis. A protein-protein interaction (PPI) network for DEGs was constructed and module analysis was performed. Finally, co-expression analysis of DEGs and lncRNAs was performed. The results of the data in the present study may provide novel insight into the roles of celecoxib in gastric cancer.

\section{Materials and methods}

Cell culture and celecoxib treatment. The human gastric carcinoma cell line NCI-N87 was obtained from the Cell Bank of the Chinese Academy of Sciences (Shanghai, China). Cells were cultured in RPMI-1640 medium (Thermo Fisher Scientific, Inc., Waltham, MA, USA) supplemented with $10 \%$ fetal bovine serum (Thermo Fisher Scientific, Inc.) and 1\% penicillin-streptomycin (Thermo Fisher Scientific, Inc.) in a 
Table IV. Top ten enriched pathways for upregulated differentially expressed genes and seven enriched pathways for downregulated DEGs.

\begin{tabular}{|c|c|c|c|}
\hline Pathway & Count & P-value & Gene symbol \\
\hline \multicolumn{4}{|l|}{ Upregulated } \\
\hline Glycolysis/gluconeogenesis & 10 & $1.03 \times 10^{-6}$ & $\begin{array}{l}\text { ACSS2, ALDH3A1, ALDOA, ENO1, ENO2, GAPDH, } \\
L D H A, P G M 1, P K M, T P I 1\end{array}$ \\
\hline Metabolic pathways & 43 & $6.04 \times 10^{-5}$ & $\begin{array}{l}\text { ACAA1, ACSL5, ACSS2, AGPAT2, AK1, AKR1B1, ALDH1A1, } \\
\text { ALDH3A1, ALDOA, ALPP, ALPPL2, ATP5G1, ATP5G3, } \\
\text { ATP6AP1, B3GNT3, CKMT1A, CKMT1B, COX8A, CYC1, } \\
\text { ECHS1, ENO1, ENO2, GAPDH, GOT1, ITPK1, LDHA, } \\
\text { MAOB, MGAT3, NDUFS3, NT5E, PGM1, PGP, PIK3C2B, } \\
\text { PKM, PLA2G4B, PLCE1, PRDX6, TPI1, TST, UGT1A6, } \\
\text { UQCRC1, UQCRC2, UQCRFS1 }\end{array}$ \\
\hline Phenylalanine metabolism & 4 & $4.00 \times 10^{-4}$ & ALDH3A1, GOT1, MAOB, PRDX6 \\
\hline Parkinson's disease & 10 & $4.67 \times 10^{-4}$ & $\begin{array}{l}\text { ATP5G1, ATP5G3, COX8A, CYC1, NDUFS3, SLC25A5, } \\
\text { UQCRC1, UQCRC2, UQCRFS1, VDAC1 }\end{array}$ \\
\hline Huntington's disease & 12 & $5.52 \times 10^{-4}$ & $\begin{array}{l}\text { ATP5G1, ATP5G3, CLTB, COX8A, CYC1, NDUFS3, } \\
\text { SLC25A5, SOD1, UQCRC1, UQCRC2, UQCRFS1, VDAC1 }\end{array}$ \\
\hline Prion diseases & 5 & $8.46 \times 10^{-4}$ & EGR1, HSPA1A, MAPK3, SOD1, STIP1 \\
\hline Oxidative phosphorylation & 9 & $2.11 \times 10^{-3}$ & $\begin{array}{l}\text { ATP5G1, ATP5G3, ATP6AP1, COX8A, CYC1, NDUFS3, } \\
\text { UQCRC1, UQCRC2, UQCRFS1 }\end{array}$ \\
\hline Alzheimer's disease & 10 & $3.16 \times 10^{-3}$ & $\begin{array}{l}\text { ATP5G1, ATP5G3, COX8A, CYC1, GAPDH, MAPK3, } \\
\text { NDUFS3, UQCRC1, UQCRC2, UQCRFS1 }\end{array}$ \\
\hline $\begin{array}{l}\text { Metabolism of xenobiotics } \\
\text { by cytochrome P450 }\end{array}$ & 6 & $4.14 \times 10^{-3}$ & $\begin{array}{l}\text { AKR1C2, AKR1C3, ALDH3A1, CYP1B1, EPHX1, } \\
\text { UGT1A6 }\end{array}$ \\
\hline Cardiac muscle contraction & 6 & $6.17 \times 10^{-3}$ & ATP1A1, COX8A, CYC1, UQCRC1, UQCRC2, UQCRFS1 \\
\hline \multicolumn{4}{|l|}{ Downregulated } \\
\hline $\begin{array}{l}\text { Epithelial cell signaling in } \\
\text { H. pylori infection }\end{array}$ & 3 & $2.92 \times 10^{-2}$ & CXCL1, CXCL8, MAP3K14 \\
\hline Complement and coagulation cascades & 3 & $3.03 \times 10^{-2}$ & C3, PLAT, SERPINA1 \\
\hline Histidine metabolism & 2 & $3.29 \times 10^{-2}$ & $A L D H 1 A 3, A O C 1$ \\
\hline $\begin{array}{l}\text { Arrhythmogenic right } \\
\text { ventricular cardiomyopathy }\end{array}$ & 3 & $3.62 \times 10^{-2}$ & ITGB6, ITGB8, PKP2 \\
\hline Axon guidance & 4 & $3.80 \times 10^{-2}$ & EFNB2, NFAT5, NTN4, SEMA7A \\
\hline Chemokine signaling pathway & 5 & $3.80 \times 10^{-2}$ & BCAR1, CXCL1, CXCL3, CXCL5, CXCL8 \\
\hline Cytokine-cytokine receptor interaction & 6 & $4.55 \times 10^{-2}$ & BMPR2, CXCL1, CXCL3, CXCL5, CXCL8, TNFRSF19 \\
\hline
\end{tabular}

DEGs, differentially expressed genes.

humidified air incubator (Thermo Fisher Scientific, Inc.) at $37^{\circ} \mathrm{C}$ and with $5 \% \mathrm{CO}_{2}$. The cells were passaged at $80-90 \%$ confluence with $0.25 \%$ trypsin (Thermo Fisher Scientific, Inc.).

Cells at the exponential growth phase with a density of $1 \times 10^{6}$ were seeded in a cell culture dish (Corning Inc., NY, USA) with a diameter of $6 \mathrm{~cm}$ and incubated in $5 \mathrm{ml}$ serum-free Dulbecco's modified Eagle medium (Thermo Fisher Scientific, Inc.) overnight. Celecoxib (Sigma-Aldrich, St. Louis, MO, USA) was dissolved in dimethylsulfoxide (DMSO; Sigma-Aldrich), and the cells were treated with $15 \mu \mathrm{M}$ celecoxib for $72 \mathrm{~h}$ (celecoxib group). Cells treated with an equal volume of DMSO were used as a control group.

RNA sequencing data. The total RNA was extracted using TRIzol (Thermo Fisher Scientific, Inc.) following the manufacturer's protocol, and were quantified with a 721 spectrophotometer
(Shanghai Precision Instrument Co., Ltd., Shanghai, China). Next, libraries were prepared by the NEBNext Ultra RNA Library Prep kit for Illumina (\#E7530; New England BioLabs, Inc., Ipswich, MA, USA) according to the manufacturer's instructions. Briefly, RNA fragments $200 \mathrm{nt}$ in length were generated and then double-stranded cDNA was synthesized and end-repaired. Following the adaptor ligation, PCR amplification was performed as follows: A library was added with $10 \mu \mathrm{l} 5 \mathrm{X}$ HF Buffer, $1 \mu 1$ $10 \mu \mathrm{M}$ reverse PCR primer 2-1: 5'-CAAGCAGAAGACGGC ATACGAGATCGTGATGTGACTGGAGTTCAGACGTGT GCTCTTCCGATCT-3' and primer 2-2: 5'-CAAGCAGAA GACGGCATACGAGATACATCGGTGACTGGAGTTCAG ACGTGTGCTCTTCCGATCT-3', primer 2-3: 5'-CAAGCA GAAGACGGCATACGAGATGCCTAAGTGACTGGAGTT CAGACGTGTGCTCTTCCGATCT-3', primer 2-4: 5'-CAA GCAGAAGACGGCATACGAGATTGGTCAGTGACTGGA 


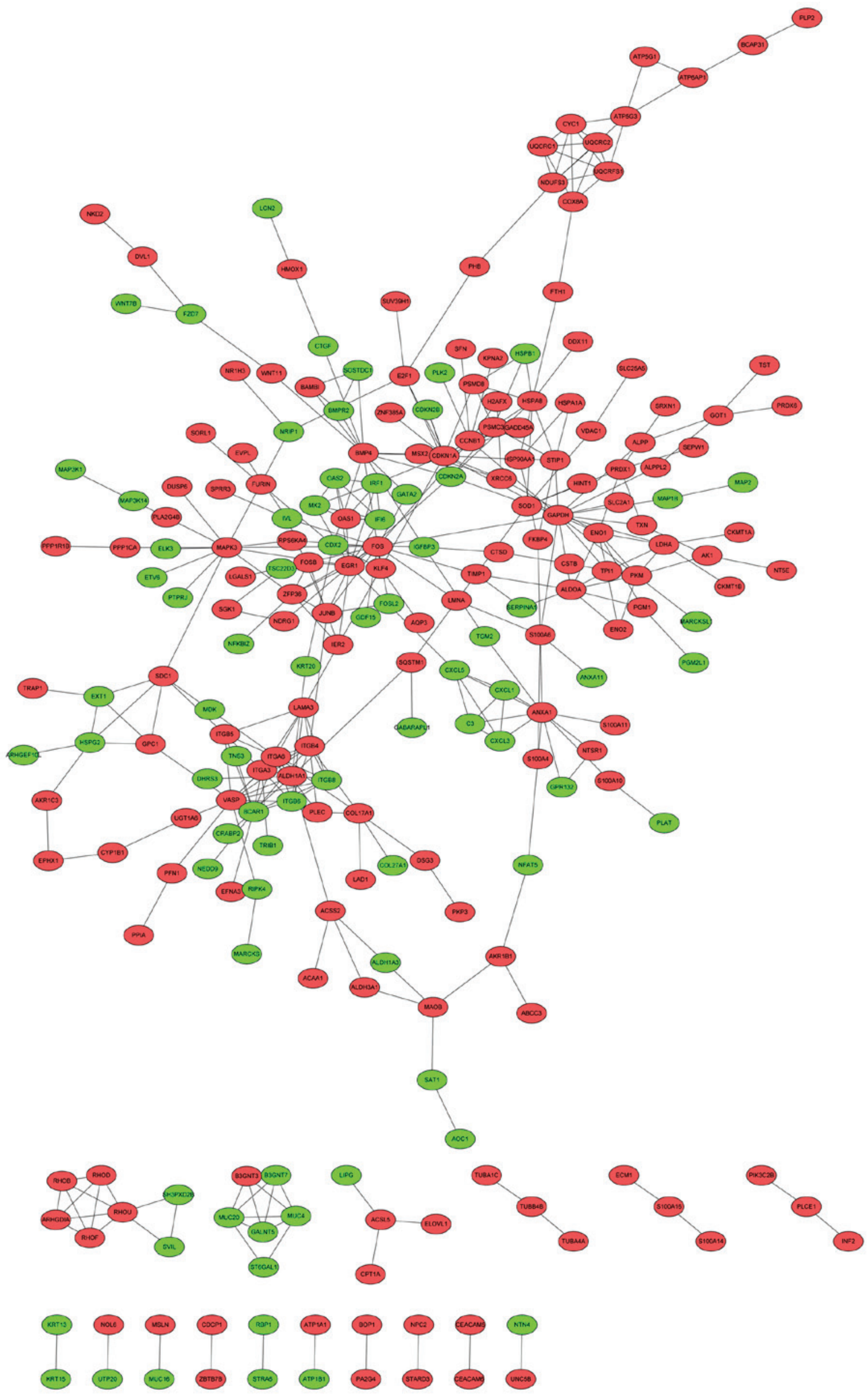

Figure 1. Constructed protein-protein interaction network for the differentially expressed genes. Red and green nodes indicate the up- and downregulated differentially expressed genes, respectively. 
Table V. Top five enriched gene ontology terms in biological process, cellular component and molecular function categories for DEGs in module 1.

A, Biological process

\begin{tabular}{|c|c|c|c|c|}
\hline GO_ID & Term & Count & P-value & DEG \\
\hline GO:0007229 & $\begin{array}{l}\text { Integrin-mediated signaling } \\
\text { pathway }\end{array}$ & 7 & $1.34 \times 10^{-14}$ & $\begin{array}{l}\text { ITGB6, BCAR1, ITGA6, ITGB4, ITGB5, } \\
\text { ITGA3, ITGB8 }\end{array}$ \\
\hline GO:0030198 & $\begin{array}{l}\text { Extracellular matrix } \\
\text { organization }\end{array}$ & 7 & $3.66 \times 10^{-10}$ & $\begin{array}{l}\text { ITGB6, LAMA3, ITGA6, ITGB4, ITGB5, } \\
\text { ITGA3, ITGB8 }\end{array}$ \\
\hline GO:0043062 & $\begin{array}{l}\text { Extracellular structure } \\
\text { organization }\end{array}$ & 7 & $3.73 \times 10^{-10}$ & $\begin{array}{l}\text { ITGB6, LAMA3, ITGA6, ITGB4, ITGB5, } \\
\text { ITGA3, ITGB8 }\end{array}$ \\
\hline $\begin{array}{l}\text { GO:0007155 } \\
\text { ITGB4, }\end{array}$ & Cell adhesion & 8 & $1.30 \times 10^{-8}$ & $\begin{array}{l}\text { ITGB6, BCAR1, LAMA3, ITGA6, } \\
\text { ITGB5, ITGA3, ITGB8 }\end{array}$ \\
\hline $\begin{array}{l}\text { GO:0022610 } \\
\text { ITGB4, }\end{array}$ & Biological adhesion & 8 & $1.35 \times 10^{-8}$ & $\begin{array}{l}\text { ITGB6, BCAR1, LAMA3, ITGA6, } \\
\text { ITGB5, ITGA3, ITGB8 }\end{array}$ \\
\hline
\end{tabular}

B, Cellular component

\begin{tabular}{lllll}
\hline GO_ID & \multicolumn{1}{c}{ Term } & Count & P-value & DEG \\
\hline GO:0008305 & Integrin complex & 6 & $3.33 \times 10^{-15}$ & ITGB6, ITGA6, ITGB4, ITGB5, ITGA3, ITGB8 \\
GO:0098636 & $\begin{array}{l}\text { Protein complex involved in } \\
\text { cell adhesion }\end{array}$ & 6 & $3.33 \times 10^{-15}$ & ITGB6, ITGA6, ITGB4, ITGB5, ITGA3, ITGB8 \\
& Receptor complex & 6 & $2.87 \times 10^{-9}$ & ITGB6, ITGA6, ITGB4, ITGB5, ITGA3, ITGB8 \\
GO:0043235 & Cell-substrate junction & 6 & $2.02 \times 10^{-8}$ & BCAR1, VASP, ITGA6, ITGB4, ITGB5, ITGA3 \\
GO:0030055 & Cell surface & 6 & $4.88 \times 10^{-7}$ & ITGB6, ITGA6,ITGB4, ITGB5, ITGA3, ITGB8 \\
GO:0009986 & & & &
\end{tabular}

C, Molecular function

\begin{tabular}{llcll}
\hline GO_ID & \multicolumn{1}{c}{ Term } & Count & P-value & DEG \\
\hline GO:0005178 & Integrin binding & 4 & $3.15 \times 10^{-7}$ & ITGB6, ITGA6, ITGB5, ITGA3 \\
GO:0050839 & Cell adhesion molecule binding & 4 & $2.35 \times 10^{-6}$ & ITGB6, ITGA6, ITGB5, ITGA3 \\
GO:0005102 & Receptor binding & 7 & $2.36 \times 10^{-6}$ & ITGB6, LAMA3, ITGA6, ITGB4, ITGB5, \\
& & & & ITGA3, ITGB8 \\
GO:0043236 & Laminin binding & 2 & $1.47 \times 10^{-4}$ & $I T G A 6, I T G A 3$ \\
GO:0050840 & Extracellular matrix binding & 2 & $4.39 \times 10^{-4}$ & $I T G A 6, I T G A 3$ \\
\hline
\end{tabular}

GO, gene ontology; DEGs, differentially expressed genes.
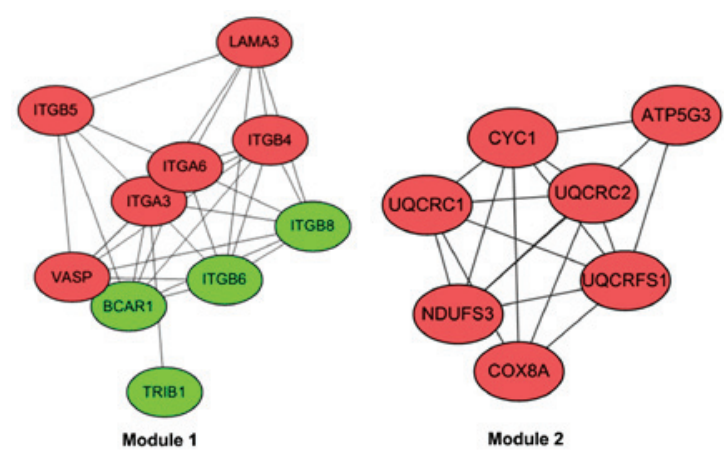

Figure 2. Two modules selected from the protein-protein interaction network. Red and green nodes indicate the up- and downregulated differentially expressed genes, respectively. 
Table VI. Top five enriched gene ontology terms in biological process, cellular component and molecular function categories for DEGs in module 2 .

\begin{tabular}{|c|c|c|c|c|}
\hline GO_ID & Term & Count & P-value & DEGs \\
\hline GO:0022904 & $\begin{array}{l}\text { Respiratory electron } \\
\text { transport chain }\end{array}$ & 6 & $4.60 \times 10^{-13}$ & $\begin{array}{l}\text { CYC1, COX } 8 A, U Q C R C 1, N D U F S 3, U Q C R C 2, \\
\text { UQCRFS1 }\end{array}$ \\
\hline GO:0022900 & Electron transport chain & 6 & $5.17 \times 10^{-13}$ & $\begin{array}{l}\text { CYC1, COX } 8 A, U Q C R C 1, N D U F S 3, U Q C R C 2, \\
\text { UQCRFS1 }\end{array}$ \\
\hline GO:0045333 & Cellular respiration & 6 & $6.05 \times 10^{-12}$ & $\begin{array}{l}\text { CYC1, COX } 8 A, U Q C R C 1, N D U F S 3, \text { UQCRC2, } \\
\text { UQCRFS1 }\end{array}$ \\
\hline GO:0015980 & $\begin{array}{l}\text { Energy derivation by oxidation } \\
\text { of organic compounds }\end{array}$ & 6 & $5.80 \times 10^{-10}$ & $\begin{array}{l}\text { CYC1, COX } 8 A, U Q C R C 1, N D U F S 3, U Q C R C 2, \\
\text { UQCRFS1 }\end{array}$ \\
\hline GO:0006091 & $\begin{array}{l}\text { Generation of precursor } \\
\text { metabolites and energy }\end{array}$ & 6 & $2.32 \times 10^{-9}$ & $\begin{array}{l}C Y C 1, C O X 8 A, U Q C R C 1, N D U F S 3, U Q C R C 2, \\
\text { UQCRFS1 }\end{array}$ \\
\hline
\end{tabular}

B, Cellular component

\begin{tabular}{|c|c|c|c|c|}
\hline GO_ID & Term & Count & P-value & DEGs \\
\hline GO:0005743 & $\begin{array}{l}\text { Mitochondrial inner } \\
\text { membrane }\end{array}$ & 7 & $1.67 \times 10^{-12}$ & $\begin{array}{l}\text { ATP } 5 G 3, C Y C 1, C O X 8 A, U Q C R C 1, N D U F S 3, \\
\text { UQCRC2, UQCRFS1 }\end{array}$ \\
\hline GO:0019866 & $\begin{array}{l}\text { Organelle inner } \\
\text { membrane }\end{array}$ & 7 & $3.57 \times 10^{-12}$ & $\begin{array}{l}\text { ATP } 5 G 3, C Y C 1, C O X 8 A, U Q C R C 1, N D U F S 3, \\
\text { UQCRC2, UQCRFS1 }\end{array}$ \\
\hline GO:0070469 & Respiratory chain & 5 & $2.12 \times 10^{-11}$ & CYC1, UQCRC1, NDUFS3, UQCRC2, UQCRFS1 \\
\hline GO:0031966 & Mitochondrial membrane & 7 & $2.30 \times 10^{-11}$ & $\begin{array}{l}A T P 5 G 3, C Y C 1, C O X 8 A, U Q C R C 1, N D U F S 3, \\
\text { UQCRC2, UQCRFS1 }\end{array}$ \\
\hline GO:0005740 & Mitochondrial envelope & 7 & $3.57 \times 10^{-11}$ & $\begin{array}{l}\text { ATP } 5 G 3, C Y C 1, C O X 8 A, U Q C R C 1, N D U F S 3 \text {, } \\
\text { UQCRC2, UQCRFS1 }\end{array}$ \\
\hline
\end{tabular}

C, Molecular function

\begin{tabular}{|c|c|c|c|c|}
\hline GO_ID & Term & Count & P-value & DEGs \\
\hline GO:0015078 & $\begin{array}{l}\text { Hydrogen ion transmembrane } \\
\text { transporter activity }\end{array}$ & 4 & $4.15 \times 10^{-8}$ & ATP5G3, COX8A, UQCRC1, UQCRFS1 \\
\hline GO:0008121 & $\begin{array}{l}\text { Ubiquinol-cytochrome-c } \\
\text { reductase activity }\end{array}$ & 2 & $3.57 \times 10^{-6}$ & UQCRC1, UQCRFS1 \\
\hline GO:0016681 & $\begin{array}{l}\text { Oxidoreductase activity, acting on } \\
\text { diphenols and related substances } \\
\text { as donors, cytochrome as acceptor }\end{array}$ & 2 & $3.57 \times 10^{-6}$ & $U Q C R C 1, U Q C R F S 1$ \\
\hline GO:0016679 & $\begin{array}{l}\text { Oxidoreductase activity, acting on } \\
\text { diphenols and related substances } \\
\text { as donors }\end{array}$ & 2 & $4.76 \times 10^{-6}$ & UQCRC1, UQCRFS1 \\
\hline GO:0015077 & $\begin{array}{l}\text { Monovalent inorganic cation } \\
\text { transmembrane transporter activity }\end{array}$ & 4 & $6.29 \times 10^{-6}$ & ATP5G3, COX8A, UQCRC1, UQCRFS1 \\
\hline
\end{tabular}

DEG, differentially expressed genes; GO, gene ontology; BP, biological process; CC, cellular component; MF, molecular function.

GTTCAGACGTGTGCTCTTCCGATCT-3', $1.5 \mu 1$ dNTP, $0.5 \mu \mathrm{l}$ Phusion High-Fidelity DNA Polymerase (2 U/ $\mu \mathrm{l})$ and $5 \mu \mathrm{l}$ $\mathrm{ddH}_{2} \mathrm{O}$, and then incubated at $98^{\circ} \mathrm{C}$ for $40 \mathrm{sec}, 65^{\circ} \mathrm{C}$ for $30 \mathrm{sec}$ and $72^{\circ} \mathrm{C}$ for $30 \mathrm{sec}$. Next, $1 \mu \mathrm{l}$ of $10 \mu \mathrm{M}$ forward PCR primer (5'-AATGATACGGCGACCACCGAGATCTACACTCTTTCC CTACACGACGCTCTTCCGATCT-3')wasaddedandincubated at $98^{\circ} \mathrm{C}$ for $10 \mathrm{sec}, 10$ cycles at $65^{\circ} \mathrm{C}$ for $30 \mathrm{sec}, 72^{\circ} \mathrm{C}$ for $30 \mathrm{sec}$, and $72^{\circ} \mathrm{C}$ for $3 \mathrm{~min}$. Finally, the library was dissolved

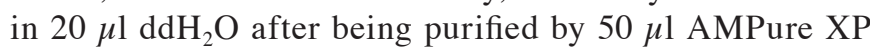
magnetic beads. A $1 \mu \mathrm{g}$ input for 15 cycles and a $5 \mu \mathrm{g}$ input for 12 cycles was used and the library quality was assessed on a 2100 Electrophoresis Bioanalyzer instrument 
Table VII. The 13 and 6 enriched pathways for differentially expressed genes in modules 1 and 2, respectively.

\begin{tabular}{|c|c|c|c|}
\hline Pathway & Count & P-value & Gene symbol \\
\hline \multicolumn{4}{|l|}{ A, Module 1} \\
\hline Focal adhesion & 9 & $5.20 \times 10^{-14}$ & $\begin{array}{l}\text { ITGB6, BCAR1, VASP, LAMA3, ITGA6, ITGB4, ITGB5, ITGA3, } \\
\text { ITGB8 }\end{array}$ \\
\hline ECM-receptor interaction & $7 \mathrm{~s}$ & $3.66 \times 10^{-12}$ & ITGB6, LAMA3, ITGA6, ITGB4, ITGB5, ITGA3, ITGB8 \\
\hline $\begin{array}{l}\text { Arrhythmogenic right } \\
\text { ventricular cardiomyopathy }\end{array}$ & 6 & $2.67 \times 10^{-10}$ & ITGB6, ITGA6, ITGB4, ITGB5, ITGA3, ITGB8 \\
\hline Hypertrophic cardiomyopathy & 6 & $5.41 \times 10^{-10}$ & ITGB6, ITGA6, ITGB4, ITGB5, ITGA3, ITGB8 \\
\hline Dilated cardiomyopathy & 6 & $8.90 \times 10^{-10}$ & ITGB6, ITGA6, ITGB4, ITGB5, ITGA3, ITGB8 \\
\hline Regulation of actin cytoskeleton & 7 & $2.55 \times 10^{-9}$ & ITGB6, BCAR1, ITGA6, ITGB4, ITGB5, ITGA3, ITGB8 \\
\hline Small cell lung cancer & 3 & $2.31 \times 10^{-4}$ & LAMA3, ITGA6, ITGA3 \\
\hline Hematopoietic cell lineage & 2 & $7.47 \times 10^{-3}$ & ITGA6, ITGA3 \\
\hline Pathways in cancer & 3 & $1.11 \times 10^{-2}$ & LAMA3, ITGA6, ITGA3 \\
\hline $\begin{array}{l}\text { Leukocyte transendothelial } \\
\text { migration }\end{array}$ & 2 & $1.27 \times 10^{-2}$ & $B C A R 1, V A S P$ \\
\hline Toxoplasmosis & 2 & $1.63 \times 10^{-2}$ & LAMA3, ITGA6 \\
\hline Cell adhesion molecules & 2 & $1.65 \times 10^{-2}$ & ITGA6, ITGB 8 \\
\hline
\end{tabular}

B, Module 2

\begin{tabular}{llll}
\hline Parkinson's disease & 7 & $2.23 \times 10^{-12}$ & ATP5G3, CYC1, COX8A, UQCRC1,NDUFS3, UQCRC2, UQCRFS1 \\
Oxidative phosphorylation & 7 & $2.49 \times 10^{-12}$ & ATP5G3, CYC1, COX8A, UQCRC1,NDUFS3, UQCRC2, UQCRFS1 \\
Alzheimer's disease & 7 & $1.33 \times 10^{-11}$ & ATP5G3, CYC1, COX8A, UQCRC1,NDUFS3, UQCRC2, UQCRFS1 \\
Huntington's disease & 7 & $2.56 \times 10^{-11}$ & ATP5G3, CYC1, COX8A, UQCRC1,NDUFS3, UQCRC2, UQCRFS1 \\
Cardiac muscle contraction & 5 & $7.02 \times 10^{-9}$ & $C Y C 1, C O X 8 A, U Q C R C 1, U Q C R C 2$, UQCRFS1 \\
Metabolic pathways & 7 & $9.66 \times 10^{-6}$ & ATP5G3, CYC1, COX8A, UQCRC1,NDUFS3, UQCRC2, UQCRFS1 \\
\hline
\end{tabular}

ECM, extracellular matrix.

(Agilent Technologies, Inc., Santa Clara, CA, USA). Finally, sequencing was conducted on a HiSeq 2500 System (Illumina, Inc., San Diego, CA, USA).

Data preprocessing and sequence alignment. Quality control (QC) of obtained next generation sequencing (NGS) data was conducted with an NGS QC Toolkit (version 2.3.3; www.nipgr.res.in/ngsqctoolkit.html) in order to remove low quality reads with default parameters (20). Reads with $\geq 10 \%$ low quality bases (Phred quality score $<20$ ) were filtered.

The paired-end RNA sequencing reads were aligned to the human hg19 reference genome using TopHat2 (ccb.jhu.edu/software/tophat) (21), and the human hg19 reference genome and its annotation files were obtained from the University of California Santa Cruz Genome Browser (genome.ucsc.edu) (22). The '-no-mixed' option was handled and other parameters were set to default.

Identification of DEGs and lncRNAs. Following sequence alignment and refseq annotation, Cuffdiff (23) was applied to screen DEGs with a cut-off criteria of $q<0.05$. DE-lncRNAs were identified with the combination of lncRNA annotation by LNCipedia 3.0 (www.Incipedia.org) (24). q<0.05 was considered as the threshold value.
Functional and pathway enrichment analysis for DEGs. Gene ontology (GO) terms in the biological process (BP), cellular component (CC) and molecular function (MF) categories were enriched for DEGs using the GO-function package in Bioconductor (www.bioconductor.org) (25). KEGG (Kyoto Encyclopedia of Genes and Genomes) pathway enrichment analysis was also conducted by the KEGG profile in Bioconductor. The enrichment thresholds were $\mathrm{P}<0.05$ and the gene counts $\geq 2$.

Construction of the PPI network and module analysis. The Search Tool for the Retrieval of Interacting Genes (STRING; www.string-db.org) database not only provides uniquely comprehensive coverage but also contains predicted, experimental, transferred and text-mined interactions (26). The PPIs for DEGs were predicted using version 9.1 of the STRING database with a combined score $>0.7$ (26). Cytoscape software version 2.8 (27) was used to visualize the PPI network (www.cytoscape.org).

The ClusterONE plugin of Cytoscape (28) was used to perform module analysis for the PPI network with default parameters. In addition, functional and pathway enrichment analysis of DEGs in the two modules with the highest significance was performed with the cut-off criteria of $\mathrm{P}<0.05$ and gene counts $\geq 2$. 


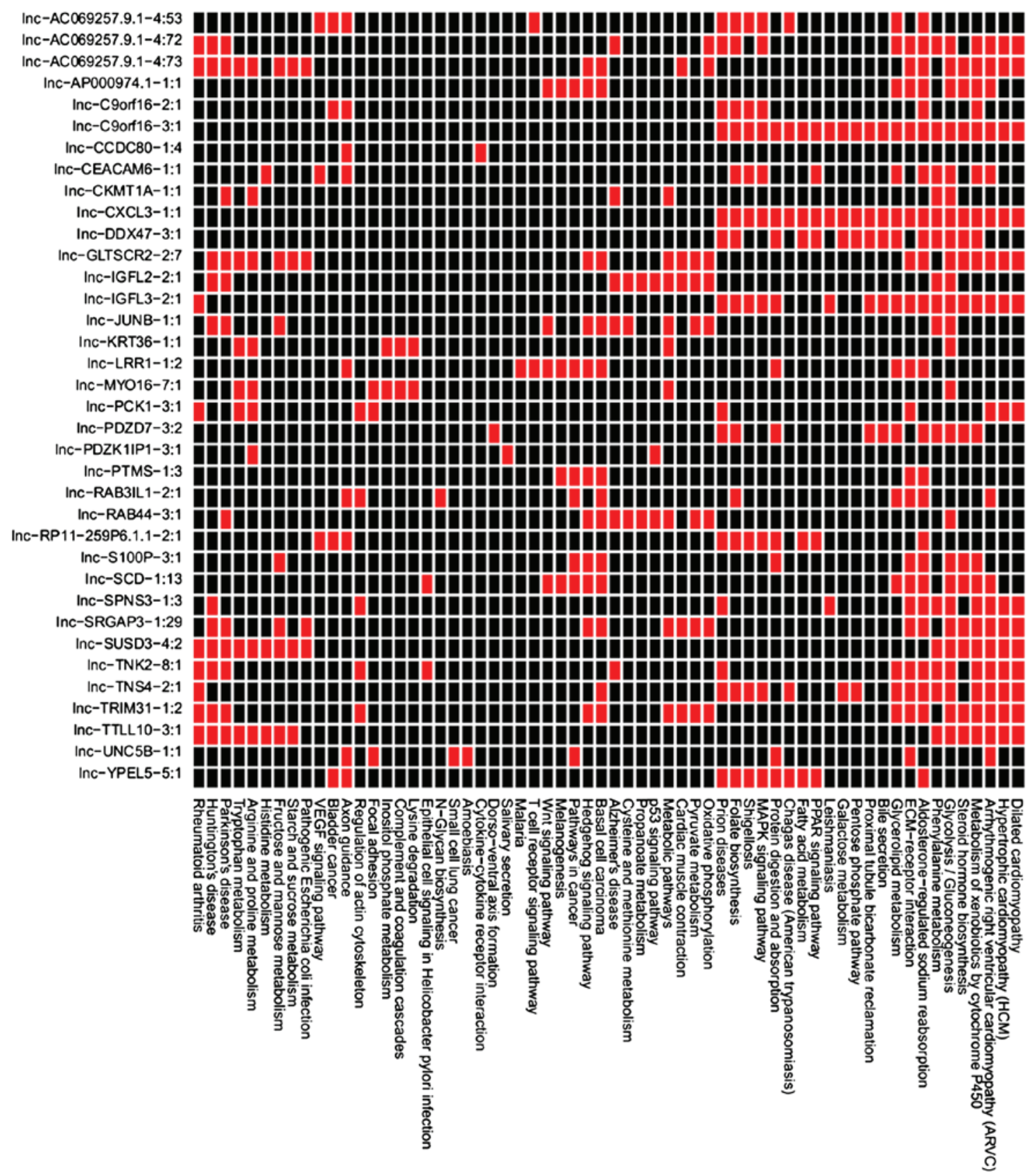

Figure 3. Enriched pathways for the differentially expressed genes co-expressed with each differentially expressed lncRNAs. Horizontal and vertical axis respectively indicate the enriched pathways and differentially expressed lncRNAs. IncRNAs, long non-coding RNAs.

Co-expression analysis of DEGs and lncRNAs. Pearson correlation coefficients between DEGs and lncRNAs were calculated. The co-expressed genes and lncRNA pairs were selected with a Pearson correlation coefficient $>0.98$. Pathway enrichment analysis was conducted for the DEGs co-expressed with each DE-lncRNA, with thresholds of $\mathrm{P}<0.05$ and gene counts $\geq 2$.

Results

DEGs and lncRNAs. A total of 490 DEGs, of which 302 were upregulated and 188 downregulated genes, were identified in the celecoxib and the control groups. A total of 37 DE-lncRNAs, of which 19 were upregulated and 18 downregulated, were screened (Table I).
Functional and pathway enrichment analysis for DEGs. GO enrichment analysis demonstrated that 672, 108 and 120 terms in the BP, CC and MF categories, respectively, were identified as upregulated genes (Table II), and 453, 45 and 67 terms were identified for downregulated genes (Table III). The most enriched GO terms in the categories for upregulated genes were as follows: BP, CC and MF categories for upregulated genes were small molecule metabolic processes $\left(\mathrm{P}=1.87 \times 10^{-9}\right)$, extracellular region $\left(\mathrm{P}=3.64 \times 10^{-23}\right)$ and protein binding $\left(\mathrm{P}=7.34 \times 10^{-7}\right)$, respectively (Table II). The most enriched GO terms in the BP, CC and MF categories for downregulated genes were tissue development $\left(\mathrm{P}=4.66 \times 10^{-8}\right)$; extracellular region $\left(\mathrm{P}=1.02 \times 10^{-10}\right)$ and protein kinase $\mathrm{C}$ binding $\left(\mathrm{P}=1.31 \times 10^{-3}\right)$, respectively (Table III). 
According to the pathway enrichment analysis, 28 and 7 pathways were identified for the upregulated and downregulated genes, respectively (Table IV). The upregulated genes were significantly enriched in the glycolysis/gluconeogenesis $\left(\mathrm{P}=1.03 \times 10^{-6}\right)$, metabolic pathways $\left(\mathrm{P}=6.04 \times 10^{-5}\right)$, phenylalanine metabolism $\left(\mathrm{P}=4.00 \times 10^{-4}\right)$, oxidative phosphorylation $\left(\mathrm{P}=2.11 \times 10^{-2}\right)$ and the metabolism of xenobiotics by cytochrome $\mathrm{P} 450\left(\mathrm{P}=4.14 \times 10^{-3}\right)$ (Table IV).

The downregulated genes were enriched in epithelial cell signaling in Helicobacter pylori infection (involving, CXCL1 and CXCL8; $\left.\mathrm{P}=2.92 \times 10^{-2}\right)$, complement and coagulation cascades $\left(\mathrm{P}=3.03 \times 10^{-2}\right)$, arrhythmogenic right ventricular cardiomyopathy $\left(\mathrm{P}=3.62 \times 10^{-2}\right)$, chemokine signaling pathway (involving CXCL1, CXCL3, CXCL5 and $\left.C X C L 8 ; \mathrm{P}=3.80 \times 10^{-2}\right)$ and cytokine-cytokine receptor interaction (involving CXCL1, CXCL3, CXCL5 and CXCL8; $\left.\mathrm{P}=4.55 \times 10^{-2}\right)($ Table IV).

PPI network and module analysis. After the PPIs of DEGs were predicted using the STRING database, the PPI network was visualized (Fig. 1). Based on the ClusterONE plugin, two modules with the highest significance (module $1, \mathrm{P}=9.96 \times 10^{-5}$, nodes $=10$; module $2, \mathrm{P}=8.98 \times 10^{-4}$, nodes $=7$ ) were selected (Fig. 2).

The DEGs in module 1 (including, ITGB6, ITGA6, ITGB4, ITGB5, ITGA3 and ITGB8) were most significantly associated with functions of the integrin complex $\left(\mathrm{CC}, \mathrm{P}=3.33 \times 10^{-15}\right)$, the protein complex involved in cell adhesion $\left(\mathrm{CC}, \mathrm{P}=3.33 \times 10^{-15}\right)$ and the integrin-mediated signaling pathway $\left(\mathrm{BP}, \mathrm{P}=1.34 \times 10^{-14}\right)$ (Table V). In module 2, DEGs were involved in the respiratory electron transport chain $\left(\mathrm{BP}, \mathrm{P}=4.60 \times 10^{-13}\right)$ and the electron transport chain $\left(\mathrm{BP}, \mathrm{P}=5.17 \times 10^{-13}\right)$ (Table VI).

The DEGs in module 1 were most significantly enriched in the focal adhesion pathway $\left(\mathrm{P}=5.20 \times 10^{-14}\right)$ and the extracellular matrix (ECM)-receptor interaction pathway $\left(\mathrm{P}=3.66 \times 10^{-12}\right)$ (Table VII). In addition, the DEGs in module 2 were enriched in Parkinson's disease $\left(\mathrm{P}=2.23 \times 10^{-12}\right)$, oxidative phosphorylation $\left(\mathrm{P}=2.49 \times 10^{-12}\right)$, Alzheimer's disease $\left(\mathrm{P}=1.33 \times 10^{-11}\right)$, Huntington's disease $\left(\mathrm{P}=2.56 \times 10^{-11}\right)$ and metabolic pathways $\left(\mathrm{P}=9.66 \times 10^{-6}\right)($ Table VII).

Co-expression analysis of DEGs and DE-lncRNAs. The pairs of co-expressed genes and lncRNAs were obtained and the enriched pathways for the DEGs co-expressed with each DE-lncRNAs are presented in Fig. 3. The DEGs co-expressed with 1nc-SCD-1:13, lnc-LRR1-1:2, Inc-PTMS-1:3, lnc-S100P-3:1, lnc-AP000974.1-1:1 and lnc-RAB3IL1-2:1 were enriched in the pathways associated with cancer, such as basal cell carcinoma, pathways in cancer and ECM-receptor interaction (Table VIII). The DEGs co-expressed with lnc-SCD-1:13, lnc-LRR1-1:2 and lnc-S100P-3:1 were enriched in the Wnt signaling pathway (Table VIII). The DEGs co-expressed with lnc-SCD-1:13, lnc-LRR1-1:2, lnc-PTMS-1:3, lnc-S100P-3:1 and lnc-AP000974.1-1:1 were enriched in the Hedgehog signaling pathway (Table VIII).

\section{Discussion}

In the present study, the RNA sequencing data between gastric cancer cells treated with celecoxib and those treated with DMSO was used to explore the mechanism of celecoxib treatment in gastric cancer cells. It has been previously demonstrated that altered patterns of DNA methylation associated with Helicobacter pylori infection of gastric epithelial cells may contribute to the risk of gastric cancer (29). Following Helicobacter pylori infection, the significant expression of CXCL5 and CXCL8 was observed in primary human gastric epithelial cells (30). Verbeke et al (31) also reported that CXC chemokines may contribute to the transition of chronic inflammation in esophageal and gastric cancer. In addition, $\mathrm{CXC}$ chemokines (CXCL1, CXCL2, CXCL3, CXCL5, CXCL6, CXCL7 and CXCL8) could promote the migration and proliferation of endothelial cells by interacting with CXCR2 (32). Furthermore, the overexpression of CXCL1 and CXCR2 may be involved in the tumor invasion in gastric cancer (33). The study by Park et al (34) demonstrated that the overexpression of CXCL5 may contribute to the pathogenesis of gastric cancer.

The results of the present study revealed that some DEGs (CXCL1 and CXCL8) were enriched in the epithelial cell signaling pathway in Helicobacter pylori infection whereas other DEGs (CXCL1, CXCL3, CXCL5 and CXCL8) were enriched in both the chemokine signaling and cytokine-cytokine receptor interaction pathways, which were consistent with the previous reports. Based on these results, CXCL1, CXCL3, CXCL5 and CXCL8 were suggested to contribute to the development of gastric cancer through multiple pathways.

ITGA3 is known to be involved in the development of gastric cancer (35). The MPS-1/ITGB4 signaling axis mediates cell migration and invasiveness, which may be used as targets during the therapy of gastric cancer (36). Song et al (35) revealed that the polymorphisms of microRNA-binding sites in the 3'UTR region of the integrin genes (ITGA3, ITGA6, ITGB3, ITGB4 and ITGB5) were associated with the susceptibility of gastric cancer. Pathway enrichment analysis revealed that integrin genes (ITGA3, ITGA6, ITGB4, ITGB5, ITGB6 and ITGB8) in module 1 were enriched in the integrin-mediated signaling pathway. Altogether, we could speculate that these integrin genes may participate in the celecoxib treatment of gastric cancer via the integrin-mediated signaling pathway.

Co-expression analysis revealed that the DEGs co-expressed with lnc-SCD-1:13, lnc-LRR1-1:2, Inc-PTMS-1:3, lnc-S100P-3:1, lnc-AP000974.1-1:1 or lnc-RAB3IL1-2:1 were enriched in a number of pathways, including ECM-receptor interaction, Wnt signaling and Hedgehog signaling pathways. A number of studies reported that lncRNAs are important in the pathogenesis of gastric cancer (37-39). Chang et al (40) revealed that the genes in the ECM-receptor interaction pathway were involved in the metastasis and aggression of gastric cancer. In addition, Tang et al (41) demonstrated that miR-200b and miR-22 could synergistically inhibit the growth of gastric cancer through the Wnt-1 signaling pathway. Furthermore, Yan et al (42) reported that the activated Hedgehog signaling pathway was involved in the progression of gastric cancer. These results implied that lnc-SCD-1:13, lnc-LRR1-1:2, lnc-PTMS-1:3, lnc-S100P-3:1, lnc-AP000974.1-1:1 and lnc-RAB3IL1-2:1 may be important in the celecoxib treatment of gastric cancer via different pathways. However, the correlation between COX-2 and DEGs or DE-lncRNAs remains unclear, and needs to be confirmed by further experiments. 
Table VIII. The DEGs co-expressed with differentially expressed lncRNAs associated with pathways in cancer.

lncRNA/pathway DEG

lnc-SCD-1:13

Wnt signaling pathway

Hedgehog signaling pathway

Basal cell carcinoma

ECM-receptor interaction

Glycolysis/gluconeogenesis

Aldosterone-regulated sodium reabsorption

Glycerolipid metabolism

Metabolism of xenobiotics by cytochrome P450

Steroid hormone biosynthesis

Epithelial cell signaling in H. pylori infection

Pathways in cancer

Arrhythmogenic right ventricular cardiomyopathy

Melanogenesis

lnc-LRR1-1:2

Wnt signaling pathway

Axon guidance

ECM-receptor interaction

Basal cell carcinoma

Aldosterone-regulated sodium reabsorption

Hedgehog signaling pathway

Malaria

Glycerolipid metabolism

$\mathrm{T}$ cell receptor signaling pathway

Pathways in cancer

Melanogenesis

Protein digestion and absorption

lnc-PTMS-1:3

Basal cell carcinoma

Aldosterone-regulated sodium reabsorption

Hedgehog signaling pathway

ECM-receptor interaction

Pathways in cancer

Melanogenesis

lnc-S100P-3:1

ECM-receptor interaction

Basal cell carcinoma

Glycolysis/gluconeogenesis

Aldosterone-regulated sodium reabsorption

Hedgehog signaling pathway

Metabolism of xenobiotics by cytochrome P450

Steroid hormone biosynthesis

Pathways in cancer

Fructose and mannose metabolism

Protein digestion and absorption

lnc-AP000974.1-1:1

Wnt signaling pathway

Hedgehog signaling pathway

Basal cell carcinoma

ECM-receptor interaction

Glycolysis/gluconeogenesis
DVL1, FZD7, NFAT5, WNT11, WNT7B

BMP4, WNT11, WNT7B

BMP4, DVL1, FZD7, WNT11, WNT7B

HSPG2, ITGA3, ITGB4, LAMA3, SDC1

ALDH1A3, ALDOA, PKM

ATP1A1, SFN, SGK1

AGPAT2, AKR1B1, LIPG

$A K R 1 C 2, A L D H 1 A 3, C Y P 1 B 1$

AKR1C2, CYP1B1, SULT2B1

ATP6AP1, CXCL8, MAP3K14

BMP4, CXCL8, DVL1, FOS, FZD7, ITGA3, LAMA3, WNT11, WNT7B

ITGA3, ITGB4, PKP2

DVL1, FZD7, WNT11, WNT7B

DVL1, NFAT5, WNT11, WNT7B

EFNA3, NFAT5, RHOD, UNC5B

ITGA3, LAMA3, SDC1

BMP4, DVL1, WNT11, WNT7B

ATP1A1, SGK1

BMP4, WNT11, WNT7B

CXCL8, SDC1

AGPAT2, AKR1B1

FOS, MAP3K14, NFAT5

BMP4, CXCL8, DVL1, FOS, ITGA3, LAMA3, SLC2A1, WNT11, WNT7B

DVL1, WNT11, WNT7B

ATP1A1, KCNE3, SLC1A5

BMP4, DVL1, WNT11, WNT7B

$S F N, S G K 1$

BMP4, WNT11, WNT7B

ITGA3, LAMA3, SDC1

BMP4, DVL1, FOS, ITGA3, LAMA3, SLC2A1, WNT11, WNT7B

DVL1, WNT11, WNT7B

ITGA3, LAMA3, SDC1

BMP4, DVL1, WNT11, WNT7B

ACSS2, ALDH1A3, ALDOA, ENO2

ATP1A1, SFN, SGK1

BMP4, WNT11, WNT7B

AKR1C2, ALDH1A3, CYP1B1

$A K R 1 C 2, C Y P 1 B 1, S U L T 2 B 1$

BMP4, CXCL8, DVL1, FOS, ITGA3, LAMA3, SLC2A1, WNT11, WNT7B

AKR1B1, ALDOA

ATP1A1, KCNE3, SLC1A5

DVL1, FZD7, NFAT5, WNT11, WNT7B

BMP4, WNT11, WNT7B

BMP4, DVL1, FZD7, WNT11, WNT7B

HSPG2, ITGA3, ITGB4, LAMA3, SDC1

ALDH1A3, ALDOA, ENO2, PKM 
Table VIII. Continued.

$\operatorname{lncRNA/pathway~}$

DEG

Aldosterone-regulated sodium reabsorption

Glycerolipid metabolism

Metabolism of xenobiotics by cytochrome P450

Steroid hormone biosynthesis

Pathways in cancer

Arrhythmogenic right ventricular cardiomyopathy

Melanogenesis

lnc-RAB3IL1-2:1

Axon guidance

Basal cell carcinoma

Extracellular matrix-receptor interaction

Aldosterone-regulated sodium reabsorption

Folate biosynthesis

Glycerolipid metabolism

N-Glycan biosynthesis

Regulation of actin cytoskeleton

Pathways in cancer

Arrhythmogenic right ventricular cardiomyopathy
ATP1A1, SFN, SGK1

AGPAT2, AKR1B1, LIPG

$A K R 1 C 2, A L D H 1 A 3, C Y P 1 B 1$

AKR1C2, CYP1B1, SULT2B1

BMP4, CXCL8, DVL1, FOS, FZD7, ITGA3, LAMA3, WNT11, WNT7B

ITGA3, ITGB4, PKP2

DVL1, FZD7, WNT11, WNT7B

lncRNA, long non-coding ribonucleic acid; DEGs, differentially expressed genes.

In conclusion, a total of 490 DEGs and 37 DE-lncRNAs were identified in the celecoxib group. Several DEGs (including CXCL1, CXCL3, CXCL5, CXCL8 and integrin genes) and DE-lncRNAs (including lnc-SCD-1:13, lnc-LRR1-1:2, lnc-PTMS-1:3, lnc-S100P-3:1, lnc-AP000974.1-1:1 and lnc-RAB3IL1-2:1) may affect celecoxib treatment of gastric cancer through different pathways. However, these results were obtained by bioinformatics analysis and require further validation.

\section{References}

1. Siegel R, Naishadham D and Jemal A: Cancer statistics, 2013. CA Cancer J Clin 63: 11-30, 2013.

2. Akagi H, Higuchi H, Sumimoto H, Igarashi T, Kabashima A, Mizuguchi H, Izumiya M, Sakai G, Adachi M, Funakoshi S, et al: Suppression of myeloid cell leukemia-1 (Mcl-1) enhances chemotherapy-associated apoptosis in gastric cancer cells. Gastric Cancer 16: 100-110, 2013.

3. Hippo Y, Taniguchi H, Tsutsumi S, Machida N, Chong JM, Fukayama M, Kodama T and Aburatani H: Global gene expression analysis of gastric cancer by oligonucleotide microarrays. Cancer Res 62: 233-240, 2002.

4. Lee CH, Bang SH, Lee SK, Song KY and Lee IC: Gene expression profiling reveals sequential changes in gastric tubular adenoma and carcinoma in situ. World J Gastroenterol 11: 1937-1945, 2005

5. Chia NY, Deng N, Das K, Huang D, Hu L, Zhu Y, Lim KH, Lee MH, Wu J, Sam XX, et al: Regulatory crosstalk between lineage-survival oncogenes KLF5, GATA4 and GATA6 cooperatively promotes gastric cancer development. Gut 64: 707-719, 2015.

6. Wadhwa R, Song S, Lee JS, Yao Y, Wei Q and Ajani JA: Gastric cancer-molecular and clinical dimensions. Nat Rev Clin Oncol 10: 643-655, 2013.

7. Wapinski $\mathrm{O}$ and Chang HY: Long noncoding RNAs and human disease. Trends Cell Biol 21: 354-361, 2011.

8. Du Z, Fei T, Verhaak RG, Su Z, Zhang Y, Brown M, Chen Y and Liu XS: Integrative genomic analyses reveal clinically relevant long noncoding RNAs in human cancer. Nat Struct Mol Biol 20: 908-913, 2013.
9. Passon DM, Lee M, Rackham O, Stanley WA, Sadowska A, Filipovska A, Fox AH and Bond CS: Structure of the heterodimer of human NONO and paraspeckle protein component 1 and analysis of its role in subnuclear body formation. Proc Natl Acad Sci USA 109: 4846-4850, 2012.

10. Song H, Sun W, Ye G, Ding X, Liu Z, Zhang S, Xia T, Xiao B, $\mathrm{Xi}$ Y and Guo J: Long non-coding RNA expression profile in human gastric cancer and its clinical significances. J Transl Med 11: 225, 2013.

11. Hu Y, Wang J, Qian J, Kong X, Tang J, Wang Y, Chen H, Hong J, Zou W, Chen Y, et al: Long noncoding RNA GAPLINC regulates CD44-dependent cell invasiveness and associates with poor prognosis of gastric cancer. Cancer Res 74: 6890-6902, 2014.

12. Liu M, Li CM, Chen ZF, Ji R, Guo QH, Li Q, Zhang HL and Zhou YN: Celecoxib regulates apoptosis and autophagy via the PI3K/Akt signaling pathway in SGC-7901 gastric cancer cells. Int J Mol Med 33: 1451-1458, 2014.

13. Lan C, Yang L, Fan L, Zhang Y, Wang J, Guo GJ, Wan S, Yang S, Wang R and Fang D: Celecoxib inhibits helicobacter pylori-induced invasion of gastric cancer cells through an adenine nucleotide translocator-dependent mechanism. Anticancer Agents Med Chem 13: 1267-1272, 2013.

14. Yeh TS, Wu CW, Hsu KW, Liao WJ, Yang MC, Li AF, Wang AM, Kuo ML and Chi CW: The activated Notch1 signal pathway is associated with gastric cancer progression through cyclooxygenase-2. Cancer Res 69: 5039-5048, 2009.

15. Hu PJ, Yu J, Zeng ZR, Leung WK, Lin HL, Tang BD, Bai AH and Sung JJ: Chemoprevention of gastric cancer by celecoxib in rats. Gut 53: 195-200, 2004.

16. Thiel A, Mrena J and Ristimäki A: Cyclooxygenase-2 and gastric cancer. Cancer Metastasis Rev 30: 387-395, 2011.

17. Pang RP, Zhou JG, Zeng ZR, Li XY, Chen W, Chen MH and $\mathrm{Hu}$ PJ: Celecoxib induces apoptosis in COX-2 deficient human gastric cancer cells through Akt/GSK3 $\beta /$ NAG-1 pathway. Cancer Lett 251: 268-277, 2007.

18. Chen Z, Liu M, Liu X, Huang S, Li L, Song B, Li H, Ren Q, Hu Z, Zhou Y and Qiao L: COX-2 regulates E-cadherin expression through the NF- $\mathrm{NB} /$ Snail signaling pathway in gastric cancer. Int J Mol Med 32: 93-100, 2013.

19. Saito Y, Suzuki H, Imaeda H, Matsuzaki J, Hirata K, Tsugawa H, Hibino S, Kanai Y, Saito H and Hibi T: The tumor suppressor microRNA-29c is downregulated and restored by celecoxib in human gastric cancer cells. Int J Cancer 132: 1751-1760, 2013. 
20. Patel RK and Jain M: NGS QC toolkit: A platform for quality control of next-generation sequencing data. Enc Metagenomics 1-5, 2013.

21. Kim D, Pertea G, Trapnell C, Pimentel H, Kelley R and Salzberg SL: TopHat2: Accurate alignment of transcriptomes in the presence of insertions, deletions and gene fusions. Genome Biol 14: R36, 2013.

22. Rosenbloom KR, Armstrong J, Barber GP, Casper J, Clawson H, Diekhans M, Dreszer TR, Fujita PA, Guruvadoo L, Haeussler M, et al: The UCSC genome browser database: 2015 update. Nucleic Acids Res 43: D670-D681, 2015.

23. Trapnell C, Roberts A, Goff L, Pertea G, Kim D, Kelley DR, Pimentel H, Salzberg SL, Rinn JL and Pachter L: Differential gene and transcript expression analysis of RNA-seq experiments with tophat and cufflinks. Nat Protoc 7: 562-578, 2012.

24. Volders PJ, Helsens K, Wang X, Menten B, Martens L, Gevaert K, Vandesompele $\mathrm{J}$ and Mestdagh P: LNCipedia: A database for annotated human lncRNA transcript sequences and structures. Nucleic Acids Res 41 (Database Issue): D246-D251, 2013.

25. Gentleman RC, Carey VJ, Bates DM, Bolstad B, Dettling M, Dudoit S, Ellis B, Gautier L, Ge Y, Gentry J, et al: Bioconductor: Open software development for computational biology and bioinformatics. Genome Biol 5: R80, 2004.

26. Franceschini A, Szklarczyk D, Frankild S, Kuhn M, Simonovic M, Roth A, Lin J, Minguez P, Bork P, von Mering C and Jensen LJ STRING v9.1: Protein-protein interaction networks, with increased coverage and integration. Nucleic Acids Res 41: D808-D815, 2013.

27. Kohl M, Wiese S and Warscheid B: Cytoscape: Software for visualization and analysis of biological networks. Methods Mol Biol 696: 291-303, 2011.

28. Nepusz T, Yu H and Paccanaro A: Detecting overlapping protein complexes in protein-protein interaction networks. Nat Methods 9: 471-472, 2012.

29. Niwa T, Tsukamoto T, Toyoda T, Mori A, Tanaka H, Maekita T, Ichinose $\mathbf{M}$, Tatematsu $\mathbf{M}$ and Ushijima T: Inflammatory processes triggered by Helicobacter pylori infection cause aberrant DNA methylation in gastric epithelial cells. Cancer Res 70: 1430-1440, 2010.

30. Mustapha P, Paris I, Garcia M, Tran CT, Cremniter J, Garnier M, Faure JP, Barthes T, Boneca IG, Morel F, et al: Chemokines and antimicrobial peptides cag-dependent early response to helicobacter pylori infection in primary human gastric epithelial cells. Infect Immun 82: 2881-2889, 2014.

31. Verbeke H, Geboes K, Van Damme J and Struyf S: The role of CXC chemokines in the transition of chronic inflammation to esophageal and gastric cancer. Biochim Biophys Acta 1825: 117-129, 2012.
32. Mukaida N, Sasaki S and Baba T: Chemokines in cancer development and progression and their potential as targeting molecules for cancer treatment. Mediators Inflamm 2014: 170381, 2014

33. Cheng WL, Wang CS, Huang YH, Tsai MM, Liang Y and Lin KH: Overexpression of CXCL1 and its receptor CXCR2 promote tumor invasion in gastric cancer. Ann Oncol 22: 2267-2276, 2011.

34. Park JY, Park KH, Bang S, Kim MH, Lee JE, Gang J, Koh SS and Song SY: CXCL5 overexpression is associated with late stage gastric cancer. J Cancer Res Clin Oncol 133: 835-840, 2007.

35. Song X, Zhong H, Zhou J, Hu X, Zhou Y, Ye Y, Lu X, Wang J, Ying B and Wang L: Association between polymorphisms of microRNA-binding sites in integrin genes and gastric cancer in Chinese han population. Tumor Biol 36: 2785-2792, 2015.

36. Yang ZY, Jiang H, Qu Y, Wei M, Yan M, Zhu ZG, Liu BY, Chen GQ, Wu YL and Gu QL: Metallopanstimulin-1 regulates invasion and migration of gastric cancer cells partially through integrin $\beta 4$. Carcinogenesis 34: 2851-2860, 2013.

37. Lin XC, Zhu Y, Chen WB, Lin LW, Chen DH, Huang JR, Pan K, Lin Y, Wu BT, Dai Y and Tu ZG: Integrated analysis of long non-coding RNAs and mRNA expression profiles reveals the potential role of lncRNAs in gastric cancer pathogenesis. Int J Oncol 45: 619-628, 2014

38. Chen S, Li P, Xiao B and Guo J: Long noncoding RNA HMlincRNA717 and AC130710 have been officially named as gastric cancer associated transcript 2 (GACAT2) and GACAT3, respectively. Tumor Biol 35: 8351-8352, 2014.

39. Okugawa Y, Toiyama Y, Hur K, Toden S, Saigusa S, Tanaka K, Inoue Y, Mohri Y, Kusunoki M, Boland CR, et al: Metastasis-associated long non-coding RNA drives cancer development and promotes peritoneal metastasis. Carcinogenesis 35: 2731-2739, 2014.

40. Chang W, Ma L, Lin L, Gu L, Liu X, Cai H, Yu Y, Tan X, Zhai Y, $\mathrm{Xu} \mathrm{X}$, et al: Identification of novel hub genes associated with liver metastasis of gastric cancer. Int J Cancer 125: 2844-2853, 2009.

41. Tang H, Kong Y, Guo J, Tang Y, Xie X, Yang L, Su Q and Xie X: Diallyl disulfide suppresses proliferation and induces apoptosis in human gastric cancer through Wnt-1 signaling pathway by up-regulation of miR-200b and miR-22. Cancer Lett 340: 72-81, 2013.

42. Yan R, Peng X, Yuan X, Huang D, Chen J, Lu Q, Lv N and Luo S: Suppression of growth and migration by blocking the hedgehog signaling pathway in gastric cancer cells. Cell Oncol (Dordr) 36: 421-435, 2013. 